\title{
Análise da efetividade de dois métodos de ensino em ressuscitação cardiorrespiratória: um estudo de coorte
}

\author{
Analysis of the effectiveness of two cardiorrespiratory resuscitation teaching methods: a \\ cohort study
}

\author{
Análisis de la eficacia de dos métodos de enseñanza de la resucitación \\ cardiorrespiratoria: un estudio cohorte
}

Rodrigo Andrade de Lima ${ }^{1}$, Sol Yasmin do Amaral Vital ${ }^{1}$, Karolliny Correa Baraúna ${ }^{1}$, Cinthya lamile Frithz Brandão de Oliveira ${ }^{1}$, Alexandre Lopes Miralha ${ }^{1 *}$.

\section{RESUMO}

Objetivo: Comparar a eficácia de dois métodos de ensino de SBV, para leigos, observando a diferença na taxa retenção de informações a curto e médio prazos. Métodos: Estudo de coorte com 28 alunos do ensino médio de escola pública na cidade de Manaus, divididos em dois grupos: Grupo A (treinamento teórico) e Grupo B (treinamento teórico-prático). A amostragem foi não probabilística e os treinamentos realizados com auxílio de materiais didáticos específicos e aplicação de pré-teste, pós-teste imediatamente após o treinamento e pós-teste após três meses. Na análise estatística os dados foram distribuídos através de médias, desvio-padrão e valores relativos. Para a comparação das médias de desempenho de ambos os grupos foi utilizado o teste t-Student, adotando-se o nível de significância de $5 \%(p<0,05)$. Resultados: Não houve diferenças estatisticamente significativas no desempenho dos dois grupos nos três momentos de avaliação. A taxa de retenção em curto prazo foi considerada excelente para os dois grupos. Em médio prazo (três meses) ficou evidente o declínio da retenção dos conteúdos teóricos, mesmo o desempenho ter sido considerado razoável. Conclusão: Concluímos ser necessário treinamentos a intervalos regulares para população leiga e que esses treinamentos sejam iniciados ainda no ensino médio.

Palavras-chave: Ensino, Parada cardíaca, Conhecimento, Aptidão, Efetividade.

\section{ABSTRACT}

Objective: To compare the effectiveness of two BLS teaching methods, for laypersons, observing the difference of the information the retention rate in the short and medium term. Methods: It is a cohort study with 28 public high school students in the city of Manaus, divided into two groups: Group A (theoretical training) and Group B (theoretical-practical training). The sampling was non-probabilistic and the training was carried out with the aid of specific teaching materials and application of a pre-test, post-test immediately after training and post-test after three months. In the analysis of statistics, the data distributed was through means, standard deviation and relative value. To compare the performance averages of both groups, the t-Student test was used, adopting a significance level of $5 \%(p<0.05)$. Results: There were no statistically significant differences in the performance of the two groups at the three assessment times. The short-term retention rate was considered excellent for both groups. In the medium term (three months) the decline in retention of theoretical content was evident, even though the performance was considered reasonable. Conclusion: We conclude that training at regular intervals is necessary for the lay population and that this training should be started in high school.

Keywords: Teaching, Heart arrest, Knowledge, Aptitude, Effectiveness.

\section{RESUMEN}

Objetivo: Comparar la efectividad de dos métodos de enseñanza BLS, para laicos, observando la diferencia en la tasa de retención de información en corto y mediano plazo. Métodos: Estudio de cohorte con 28 estudiantes de secundaria pública de la ciudad de Manaus, divididos en dos grupos: Grupo A (capacitacíon teórica) y Grupo B (capacitacíon teóricopráctica). El muestreo fue no probabilístico y la capacitacíon se realizó con ayuda de materiales didácticos específicos y aplicación de un pre-test, post-test inmediatamente después del entrenamiento y post-test a los tres meses. En el análisis estadístico, los datos se distribuyeron mediante medias, desviación estándar y valores relativos. Para comparar los promedios de desempeño de ambos grupos se utilizó la prueba t-Student, adoptando un nivel de significancia del $5 \%$ ( $p$ $<0.05)$. Resultados: No hubo diferencias estadísticamente significativas en el desempeño de los dos grupos en los tres momentos de evaluación. La tasa de retención a corto plazo se consideró excelente para ambos grupos. En el mediano plazo (tres meses) se evidenció el descenso en la retención de contenidos teóricos, aunque el desempeño se consideró razonable. Conclusion: Concluimos que la capacitacíon a intervalos regulares es necesaria para la población laica y que dicha capacitacíon debe iniciarse en el bachillerato.

Palabras clave: Docencia, Paro cardiaco, Conocimiento, Aptitud física, Eficacia.

${ }^{1}$ Universidade Federal do Amazonas, Manaus - AM. *E-mail: alexmiralha@hotmail.com 


\section{INTRODUÇÃO}

A parada cardiorrespiratória (PCR) é a cessação súbita da atividade cardíaca e/ou respiratória com possibilidade de recuperação das funções cardiopulmonar e cerebral (GONZALEZ MM, et al., 2013; AEHLERT B, et al., 2003; AMERICAN HEART ASSOCIATION, 2020). Estudos apontam que aproximadamente 300.000 pessoas apresentam parada cardíaca extra-hospitalar nos Estados Unidos anualmente (BOBROW BJ, et al., 2011). Na Europa, 275.000 pessoas morrem devido a ressuscitação cardiopulmonar (RCP) malsucedida após PCR fora do hospital (WINGER S, et al., 2018). No Brasil, especificamente no estado do Amazonas, segundo dados do Ministério da Saúde, em 2015 foram registradas 2.950 mortes relacionadas ao Infarto Agudo do Miocárdio (IAM) e suas complicações, grande parte em ambiente extra-hospitalar (TABNET-DATASUS).

Nesse contexto, o Suporte Básico de Vida (Basic Life Support - BLS), consiste em um curso prático do tipo hands-on criado pela American Heart Association (AHA) com a finalidade de ensinar o método de identificação e ação imediata diante de uma PCR (PERGOLA AM e ARAUJO IEA, 2009). Esse curso, já difundido em muitos países para treinamento de médicos, enfermeiros e outros profissionais da saúde e para leigos, ajuda a melhorar a sobrevida após o evento súbito de colapso cardiopulmonar (WISSENBERG M, et al., 2013; PERGOLA AM e ARAUJO IEA, 2009; AMERICAN HEART ASSOCIATION, 2020).

Por se tratar de uma situação extrema e transversal a todas as áreas da saúde, a PCR deve ser identificada e atendida de forma imediata para melhorar a sobrevivência sem sequelas (GONZALEZ MM, et al., 2013; AEHLERT B, 2013). Alguns autores (WINGER S, et al., 2018; AMERICAN HEART ASSOCIATION, 2020; TONY ACC, et al., 2020) referem que entre $70-80 \%$ dos óbitos, devido à PCR em ambiente extra-hospitalar, são motivados pelo não reconhecimento dos sinais e sintomas apresentados durante o evento concorrendo para piores desfechos, com sequelas neurológicas ou óbito (SASSON C, et al., 2010; WISSENBERG M, et al., 2013; WINGER S, et al., 2018).

Isbye DL, et al. (2007) comparando a retenção de informações sobre suporte básico entre adultos e crianças, verificaram que apesar dos adultos terem apresentado desempenho significativamente melhor em quase todas as variáveis, as crianças demonstraram desempenho melhor nas variáveis "compressões totais" $(p<0,001)$ e "tempo sem intervenção" $(p<0,001)$, sem haver diferenças entre os dois grupos com as variáveis "razão ventilação-compressão" e "posição das mãos".

$\mathrm{Na}$ Irlanda do Norte, um programa de SBV desenhado para treinamento de professores da educação básica por estudantes de medicina mostrou, através da aplicação de questionário, que alunos na faixa etária de 10 a 12 anos, que se encontravam na 7a série, podem ser treinados adequadamente por professores que passaram a se tornar agentes multiplicadores com bons resultados (TONER ACC, et al., 2007).

Diferentemente, Haseneder R, et al. (2019) mostrou que apesar do treinamento em SBV ter proporcionado ganhos de curto prazo no conhecimento e autoconfiança, esses fatores declinaram progressivamente 9 meses após a sessão de treinamento. Nesse mesmo estudo os alunos treinados por instrutores estudantes de medicina tiveram melhor aprendizado em relação os instrutores médicos com experiência em emergência.

Stroobants J, et al. (2014) investigando o impacto do ensino de manobras de RCP em crianças na idade escolar e seus familiares levou a uma atitude mais positiva em relação a RCP. Nesse estudo os resultados foram mais positivos com estagiários de alunos do ensino fundamental do que com estagiários de alunos do ensino médio. Esses dados demonstram a importância de programas de educação em RCP para crianças e adolescentes em idade escolar, que há mais de uma década vêm sendo implementados com comprovação científica em vários países (ISBYE DL, et al., 2007; TONER P, et al., 2007; WINGEN S, et al., 2018; TONY ACC, et al., 2020).

O emprego efetivo do SBV/BLS depende de muitos fatores e o principal deles é o ensino correto e o treinamento periódico de suas técnicas para a manutenção das habilidades psicomotoras necessárias para a execução de manobras, tais como, reconhecimento da PCR, aplicação de compressões torácicas, abertura de via aérea, ventilações de resgate e palpação do pulso. Existem atualmente várias formas de difusão desse conhecimento, sendo as mais prevalentes o método hands-on (teórico-prático) que utiliza manequins 
simuladores na elaboração de cenários clínicos interativos, e o método expositivo (teórico), que consiste na visualização teórica dos possíveis cenários de uma PCR através de recursos audiovisuais (CUMMINS RO, et al., 1991; AMERICAN HEART ASSOCIATION, 2020).

Sendo assim, o objetivo primário desse estudo foi comparar o desempenho de dois métodos de ensino de reanimação cardiorrespiratória (RCP) entre leigos (adolescentes), bem como determinar se há diferença na qualidade da aquisição cognitiva a curto e médio prazo observando a taxa de retenção de informação em cada um dos grupos.

\section{MÉTODOS}

Estudo epidemiológico do tipo observacional de coorte prospectivo em um colégio do ensino médio localizado na cidade de Manaus entre os meses de dezembro de 2018 a abril de 2019. Foram selecionados 28 alunos do Colégio Militar da Polícia Militar de Manaus, entre 14 e 18 anos alocados em dois grupos: Grupo A (recebeu apenas treinamento teórico) e Grupo B (treinamento teórico e prático). Cada grupo recebeu treinamento sobre Reanimação Cardiopulmonar Hands Only e Desfibrilação Externa Automática, com base nas diretrizes de Suporte Básico de Vida da American Heart Association atualizadas e publicadas em 2015.

Para o cálculo amostral através do software OpenEpi, disponível em https://www.openepi.com/Menu/OE_Menu.htm, foram considerados: poder do teste de $80 \%$, intervalo de confiança de $95 \%$ e razão do tamanho da amostra (Grupo A/ Grupo B) igual a 1 com erro amostral de $5 \%$ e desvio padrão de \pm 5 entre as médias. O número de participantes foi estimado em 32 de um universo de 60 alunos considerando as duas turmas. Participaram do estudo 28 estudantes randomizados em dois grupos pela coordenadora pedagógica sem cegamento através da listagem das turmas. Os alunos do Grupo $A$ pertenciam ao segundo ano do ensino médio e os alunos do Grupo B pertenciam do terceiro do ensino médio.

Os critérios de inclusão foram: estar matriculado em uma das duas séries escolhidas para o treinamento e assinatura do TCLE (Termo de Consentimento Livre e Esclarecido) pelos pais. Foram excluídos da pesquisa os alunos: com histórico prévio de palestras ou treinamento em SBV ou contato com a equipe coordenadora do estudo; aluno cujo responsável não tenha assinado o TCLE.

Para a pesquisa foi utilizada apresentação em power point abordando os aspectos teóricos e práticos do Programa de Suporte Básico de Vida através de seus cursos CPR Family and friends, CPR and first Ads da American Heart Association (AHA), que norteiam a divulgação das técnicas entre leigos. Ambos os grupos receberam a mesma instrução teórica presencial na escola. Para o treinamento prático, foram utilizados manequins Ressusci Junior da marca Laerdal® com mecanismo de feedback em tempo real pertencentes ao Projeto de Extensão ReanimAÇÃO vinculado ao Laboratório de Habilidades e Simulação Realística da Faculdade de Medicina da Universidade Federal do Amazonas.

O treinamento presencial teve duração média de 120 minutos e realizado no mesmo dia em horários seguidos. Foram aplicadas avaliações teóricas em três momentos: pré-teste e pós-teste imediatamente antes e após três meses para ambos os grupos. Os testes realizados foram idênticos, com 15 quesitos de múltipla escolha, contendo quatro alternativas, com uma correta. Não houve avaliação do desempenho prático após 3 meses.

A variável desfecho do estudo foi a média de acertos nas avaliações. As variáveis quantitativas foram descritas através de média e desvio padrão e a diferença do desempenho em cada um dos momentos avaliados foi comparada entre os grupos através do teste $t$-Student para comparar a média de acertos grupos (A e B), sendo o valor de $p<0,05$.

Além das questões de múltipla escolha, as avaliações continham o número de matrícula do discente, a idade (em anos) e o sexo (se masculino ou feminino). Os dados foram preenchidos pelos próprios sujeitos da pesquisa durante o treinamento, sendo todas as informações organizadas em planilha no programa Excel e analisadas pelo programa SPSS (Statistical Package for the Social Sciences).

Durante a aplicação de todos os testes não foi permitido nenhum auxílio por parte da equipe da pesquisa. Os temas relacionados a cada uma das questões encontram-se descritos na legenda das figuras 01 e 02 na seção a seguir. 
O projeto foi submetido à Plataforma Brasil e aprovado sob o parecer número 3.005.294 em 08 de novembro de 2018 (CAAE № 99870918.8.0000.5020).

\section{RESULTADOS}

Os grupos A e B foram compostos por 14 alunos cada um de um total 60 participantes potencialmente elegíveis (30 em cada turma da escola). Foram incluídos 28 alunos, sendo que todos estes terminaram o acompanhamento e foram efetivamente avaliados. Apesar de serem alunos de duas séries diferentes, os grupos foram considerados homogêneos entre si (Tabela 1).

Tabela 1 - Características demográficas dos 28 participantes da pesquisa por grupo submetidos ao treinamento em Suporte Básico de Vida, no Colégio da Polícia Militar, no período de dezembro de 2018 a junho de 2019, Manaus /Amazonas.

\begin{tabular}{|c|c|c|c|c|c|c|}
\hline \multirow{3}{*}{\multicolumn{3}{|c|}{$\begin{array}{l}\text { Número de participantes } \\
\text { e Idade média dos participantes }\end{array}$}} & \multicolumn{4}{|c|}{ Frequência do sexo entre os participantes } \\
\hline & & & \multicolumn{2}{|c|}{ Masculino } & \multicolumn{2}{|c|}{ Feminino } \\
\hline & & & $\mathbf{N}$ & $\%$ & $\mathbf{N}$ & $\%$ \\
\hline $\begin{array}{l}\text { GRUPO A (treinamento } \\
\text { exclusivamente teórico) } \\
2^{\underline{a}} \text { série }\end{array}$ & 14 & $15,5 \pm 0,51$ & 5 & 35,7 & 9 & 64,3 \\
\hline $\begin{array}{l}\text { GRUPO B (treinamento } \\
\text { teórico-prático) } \\
3^{\underline{a}} \text { série }\end{array}$ & 14 & $16,35 \pm 0,49$ & 7 & 50 & 7 & 50 \\
\hline Total & 28 & $15,92 \pm 0,66$ & 12 & 42,9 & 16 & 57,1 \\
\hline
\end{tabular}

Fonte: Lima RAD, et al., 2021.

Figura 1 - Comparação de desempenho do Grupo A no pré-teste, pós-teste imediato e pós-teste 3 meses depois.

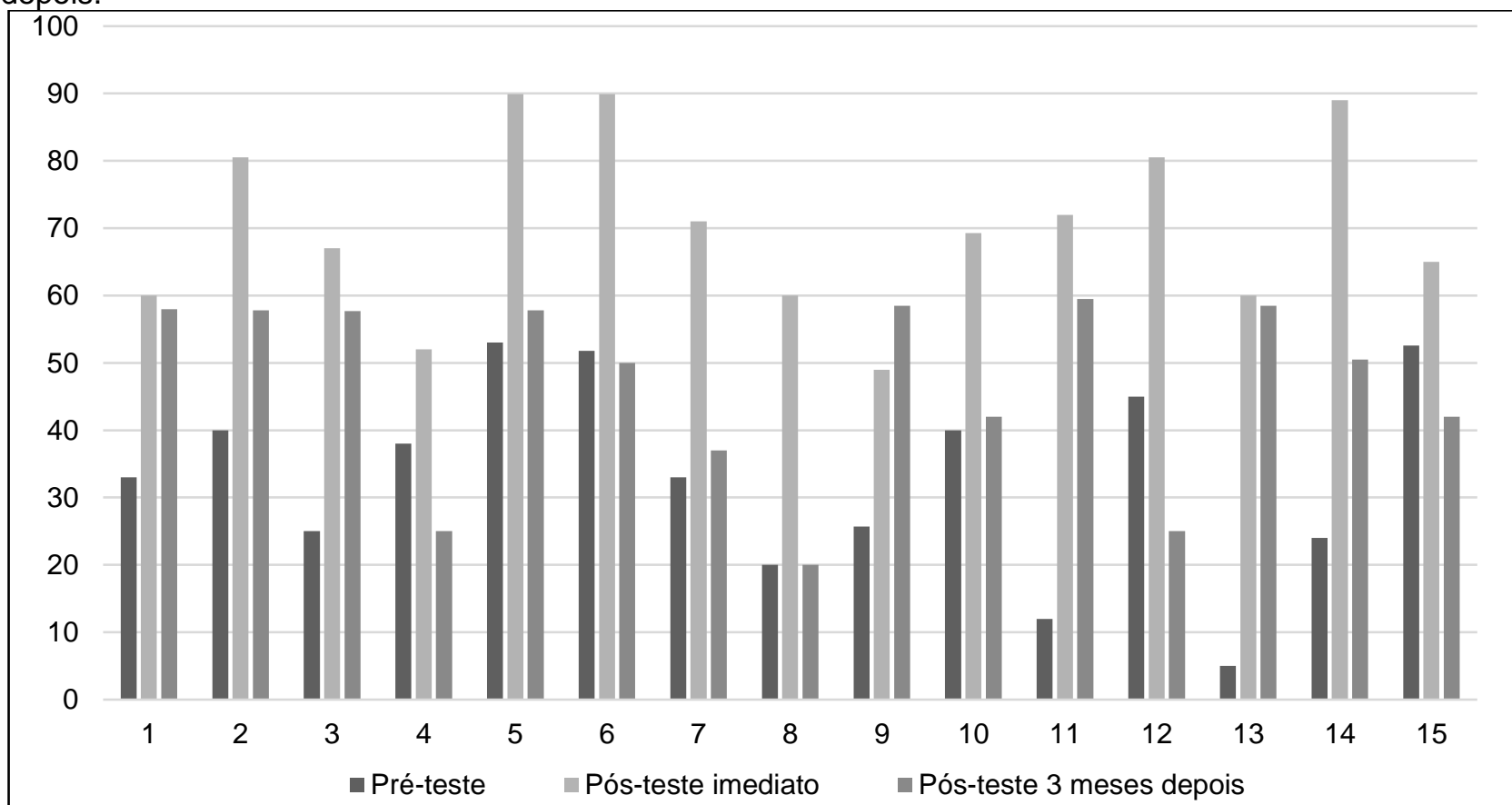

Legenda: As colunas representam as questões das 3 avaliações (pré-teste, pós-teste imediato e pós-teste após 3 meses do treinamento) com os seguintes temas: Questão 1 - Realização da compressão torácica; Questão 2 - Identificar a vítima inconsciente; Questão 3 - Importância do estudo do tema; Questão 4 Segurança da cena; Questão 5 - Abordagem de se comunicar com o serviço de emergência (Ativação do SME*); Questão 6 - Sinais de Vida; Questão 7 - Conduta frente a pessoa em apneia; Questão 8 - Correto posicionamento das mãos para compressão torácica; Questão 9 - Manobras de abertura da via aérea; Questão 10 - Relação ventilação e compressões; Questão 11 - Início das compressões em indivíduo inconsciente; Questão 12 - O que falar ao SME; Questão 13 - Maneira adequada de aplicar compressão torácica; Questão 14 - Número do SME; Questão 15- Sequência da reanimação cardiorrespiratória. *SME Serviço Médico de Emergência (SAMU). Fonte: Lima RAD, et al., 2021. 
Em relação ao Grupo A, o nível de acertos no pré-teste variou de razoável a baixo. Das 15 questões, em 8 os alunos apresentaram o rendimento médio entre 20 e 40\%. Em 3 questões o percentual de acertos ficou entre 0 e 20\%, sendo que somente em 4 questões houve rendimento entre 40 e $60 \%$. Em relação ao pósteste aplicado logo após o treinamento, observamos que houve mudança no nível e acerto das questões. $O$ que antes não ocorreu, neste momento verificou-se que em 5 das 15 questões, os alunos apresentaram taxa de acerto entre 50 e $75 \%$, sendo apenas uma questão com desempenho insatisfatório. Já a porcentagem de acertos do grupo do treinamento exclusivamente teórico três meses após o treinamento foi mediano. Das 15 questões, 3 foram as questões em que o rendimento médio dos alunos ficou entre 20 e 30\%. Já em 5 questões o rendimento ficou entre 30 e 50\%, sendo que em 7 questões houve rendimento entre 50 e $60 \%$ (Figura 1).

Figura 2 - Comparação de desempenho do Grupo B no pré-teste, pós-teste imediato e pós-teste 3 meses depois.

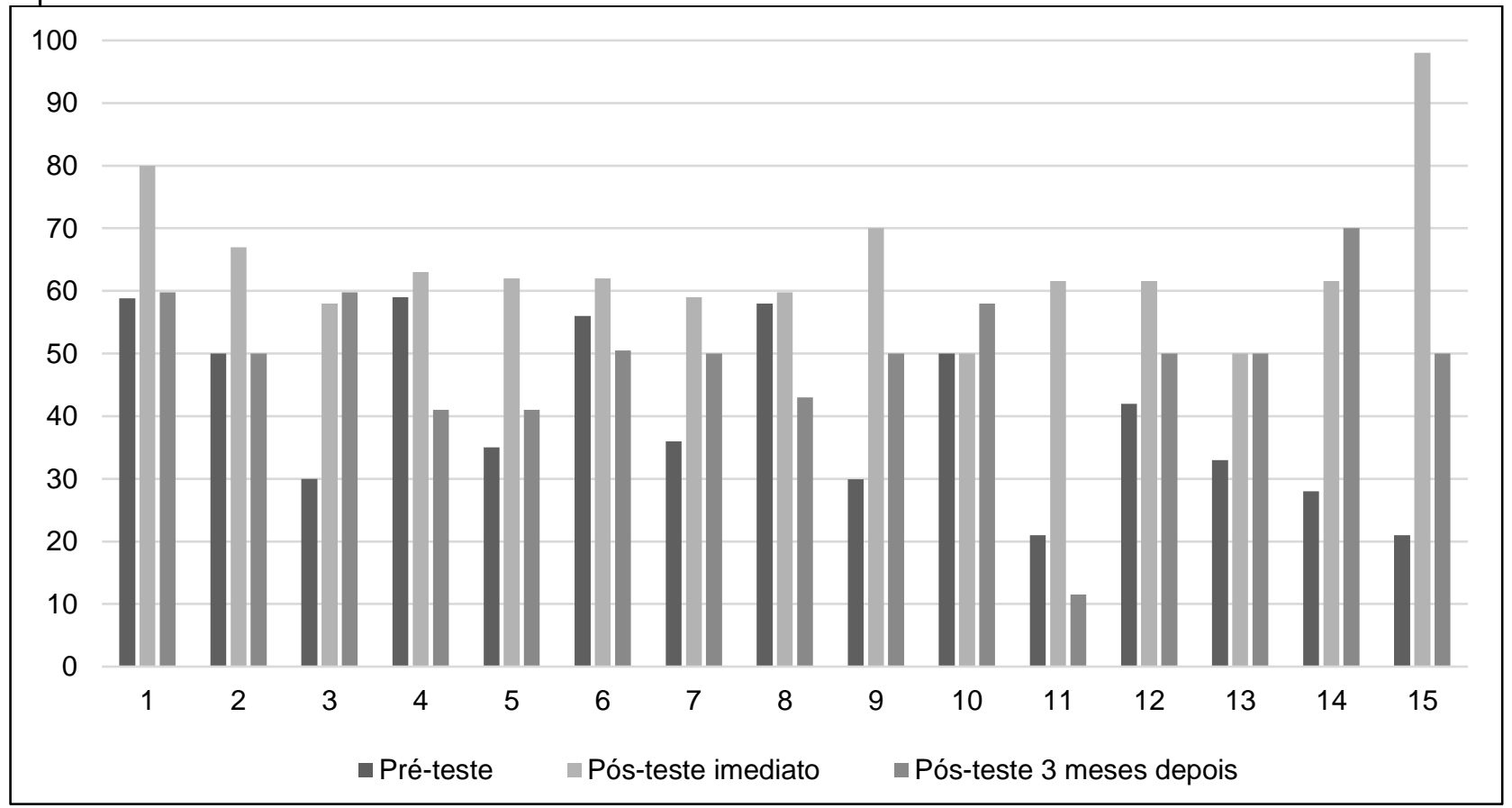

Legenda: As colunas representam as questões das 3 avaliações (pré-teste, pós-teste imediato e pós-teste após 3 meses do treinamento) com os seguintes temas: Questão 1 - Execução da compressão torácica; Questão 2 - Primeiro passo após encontrar alguém inconsciente; Questão 3 - Importância do estudo do tema; Questão 4 - Segurança da cena; Questão 5 - Abordagem de se comunicar com o serviço de emergência; Questão 6 - Sinais de Vida; Questão 7 - Conduta frente a pessoa em apneia; Questão 8 - Correta posição para compressão torácica; Questão 9 - Manobras para abrir via aérea; Questão 10 - Relação ventilação e compressões; Questão 11 - Início das compressões em indivíduo inconsciente; Questão 12 - O que falar ao SAMU; Questão 13 - Maneira adequada de aplicar compressão torácica; Questão 14 - Número do SAMU; Questão 15- Sequência da reanimação cardiorrespiratória. *SME - Serviço Médico de Emergência (SAMU). Fonte: Lima RAD, et al., 2021.

Em relação ao Grupo B, a porcentagem de acertos no período anterior ao treinamento teórico-prático variou de razoável para baixo. Das 15 questões, 8 foram as questões em que o rendimento médio dos alunos ficou entre 20 e $40 \%$. Já em 3 questões o rendimento ficou entre 40 e $50 \%$, sendo que somente 4 questões tiveram rendimento entre 50 e $60 \%$. Já a porcentagem de acertos em relação ao período imediatamente posterior ao treinamento teórico-prático variou de razoável para alta.

Das 15 questões, 5 foram as questões em que o rendimento médio dos alunos ficou entre 50 e $60 \%$. Já em 9 questões o rendimento ficou entre 60 e $80 \%$, sendo que somente 1 questão teve rendimento entre 80 e $100 \%$. Três meses após o treinamento o rendimento da turma foi mediano. Das 15 questões, 11 foram as questões em que o rendimento médio dos alunos ficou entre 20 e $50 \%$. Já em 3 questões o rendimento ficou entre 50 e 60\%, sendo que somente uma questão teve rendimento entre 60 e $80 \%$ (Figura 2). 
Fez-se uma comparação das médias do desempenho entre os dois grupos, por meio da média de acertos nas questões variando de 0 a 15 nos seguintes momentos: antes do treinamento, imediatamente após e três meses após o treinamento (Tabela 2).

Tabela 2 - Comparação das médias do desempenho antes, imediatamente após e três meses após o treinamento exclusivamente teórico versus teórico-prático.

\begin{tabular}{cccc}
\hline $\begin{array}{c}\text { Momento da aplicação do } \\
\text { questionário }\end{array}$ & $\begin{array}{c}\text { Média do grupo } \\
\text { teórico (Grupo A) }\end{array}$ & $\begin{array}{c}\text { Média do grupo teórico- } \\
\text { prático (Grupo B) }\end{array}$ & Valor $\mathbf{p}$ \\
\hline Antes do treinamento & $4,93 \pm 1,52$ & $5,23 \pm 1,92$ & 0,856 \\
\hline $\begin{array}{c}\text { Imediatamente após o } \\
\text { treinamento }\end{array}$ & $10,46 \pm 1,82$ & $11,54 \pm 1,21$ & 0,902 \\
\hline $\begin{array}{c}\text { Três meses após o } \\
\text { treinamento }\end{array}$ & $7,07 \pm 1,29$ & $7,85 \pm 1,89$ & 0,681 \\
\hline
\end{tabular}

Fonte: Lima RAD, et al., 2021

\section{DISCUSSÃO}

A PCR extra hospitalar é uma das principais causas de mortes na Europa e nos Estados Unidos. Nas diretrizes do Conselho Europeu de Ressuscitação, em 2015 houve um destaque especial para o início imediato das manobras de ressuscitação cardiopulmonar por quem presencia o evento súbito (BOBROW BJ, et al., 2011; AMERICAN HEART ASSOCIATION, 2020).

De acordo com o consenso internacional, a presença de um socorrista treinado, pronto, disposto e capaz de agir é fator determinante para a sobrevivência pós-parada cardíaca (SASSON C, et al., 2010; WINGER S, et al., 2018). O início do treinamento de RCP na idade escolar é intervenção segura e eficaz para melhorar as taxas de sobrevivência pós-PCR fora do hospital em duas a quatro vezes (WISSENBERG M, et al., 2013; FERNANDE JMG, et al., 2014; FINKE SR, et al., 2018; HASENEDER R, et al., 2019).

Baseando-se no fato de que o melhor momento de introduzir o ensino do suporte básico de vida é na infância, foi divulgada a declaração conjunta "Kids save lives", endossada pela OMS em janeiro de 2015, que visa introduzir o treinamento anual em RCP como conteúdo curricular às crianças em idade escolar em todo o mundo (BOTTIGER BW e AKEN HV, 2015).

Esse estudo foi realizado a partir da dúvida sobre a forma mais eficiente e de melhor custo-benefício para a realização periódica de treinamentos de SBV direcionado ao público leigo, com ênfase nos jovens. A ausência desse conteúdo é a regra na maioria das escolas públicas e privadas na cidade de Manaus, o que não é diferente para outras localidades da região. Os métodos de ensino sobre RCP já vêm sendo estudados há algum tempo, tendo em vista a relevância da abordagem do tema desde os primeiros anos da educação formal como estratégia de incorporação na sociedade das ações necessárias para a prestação dos primeiros cuidados na vigência de um evento súbito extra-hospitalar (CUMMINS RO, et al., 1991BOBROW BJ, et al., 2011; FERNANDE JMG, et al., 2014)

Sabemos que o treinamento teórico-prático, quando comparado ao teórico apenas, é caro e exige infraestrutura e logística. Com isso, uma comparação prática dos dois métodos pode ajudar a determinar qual deve ser adotado por instituições que desejam realizar treinamentos regulares para um público-alvo em questão. Esse trabalho trata-se de um estudo inédito na cidade de Manaus, coadunando com outros estudos realizados em outras regiões do país (MIOTTO HC, et al., 2010; RIBEIRO LG, et al., 2013).

Os resultados apontam que o conhecimento prévio de ambos os grupos sobre a RCP era de médio abaixo. No pré-teste, o Grupo A (Figura 1), teve melhor rendimento sobre a comunicação com o serviço de emergência e a correta execução da sequência (passo a passo) da RCP. Os temas que tiveram pior rendimento (questões 11 e 13) tratavam do início das compressões torácicas e de como elas devem ser aplicadas. O pior rendimento dessas questões pode ser explicado, em parte, pela dificuldade do leigo em verificar o pulso carotídeo e pela necessidade do conhecimento de que a compressão torácica deve ser realizada com força e rapidez. Ressalta-se, ainda, que a informação sobre o local de palpação do pulso apesar 
de ter sido ensinada, a AHA não enfatiza pelas dificuldades de identificação do pulso por parte dos leigos, com piores desfechos (AMERICAN HEART ASSOCIATION, 2020).

A dificuldade dos sujeitos da pesquisa em relação à compressão torácica também foi vista na literatura (FINKE SR, et al., 2018; RIBEIRO LG, et al., 2013; LAU Y, et al., 2018), sendo observado que o conhecimento a respeito da ventilação, da compressão torácica e do uso do desfibrilador externo automático (DEA) antes do treinamento apresentava melhor desempenho para a ventilação, em relação aos demais.

No que se refere ao desempenho do Grupo B, no pré-teste (Figura 2), as questões com melhor escore versavam sobre a posição das mãos para iniciar as compressões torácicas e sinais de vida. A exposição através da mídia e filmes do número do Serviço de Atenção Móvel de Urgência (SAMU) e de profissionais da saúde realizando as compressões torácicas pode ser uma possível explicação para o melhor desempenho nessas temáticas (GORDON PN, et al., 1998; HAINZENREDER TB, et al., 1996). O pior desempenho nesse grupo esteve relacionado ao início das compressões torácicas no indivíduo inconsciente.

No pós-teste imediato do Grupo A (Figura 1), o melhor desempenho foi para os sinais de vida, número do SAMU e o que falar ao telefone para o atendente do SAMU. O estudo de Lau Y, et al. (2018) utilizou essas temáticas agrupadas em "conhecimento geral" e atestou que, em comparação aos conhecimentos específicos (ventilação, compressão torácica e DEA), a população teve melhor desempenho no conhecimento geral, tanto antes, quanto depois do treinamento, concordando com os nossos achados. No pós-teste imediato do Grupo B (Figura 2), o melhor escore foi nas questões relativas à execução correta da compressão torácica. Esse resultado, concordante com o estudo de Finke SR, et al. (2018), pode ter ter tido influência do treinamento prático efetuado na consolidação desse conhecimento específico da RCP.

No pós-teste do Grupo A, realizado três meses após (Figura 1), as questões com melhor escore foram: como checar os sinais vitais, número do SAMU e a importância do estudo da RCP. Nesse momento o conceito mais esquecido foi em relação à posição para compressões torácicas. Em relação ao Grupo $\mathrm{B}$, podemos destacar que houve perda de desempenho, comparado ao pré-teste, nos temas de segurança da cena, abordagem de se comunicar com o serviço de emergência, correta posição para compressão torácica e início das compressões em indivíduo inconsciente. Porém, relacionado à importância do estudo do tema, conduta frente à pessoa em apneia, manobras para abrir via aérea, maneira adequada de aplicar compressão, número do SAMU e sequência da reanimação cardiorrespiratória, o grupo apresentou melhor pontuação

É fato que houve declínio no desempenho entre os pós-testes realizados três meses após o treinamento tanto entre alunos do Grupo A quanto do Grupo B. A diferença percentual entre sexo masculino e feminino não foi vista como um fator que pudesse ter influenciado no desempenho (Tabela 1), uma vez que o pósteste realizado foi eminentemente teórico ainda que sobre aspectos práticos da SBV. A literatura mostra que estudantes do sexo feminino parecem ser mais motivadas para o treinamento e com melhor capacidade disseminadora do conhecimento em relação aos estudantes do sexo masculino, que por sua vez apresentam melhores chances em atingir melhor nível de proficiência na frequência e profundidade das compressões torácicas quando avaliados durante a execução das manobras, fato esse provavelmente ligado a fatores constitucionais nessa faixa etária (MIOTTO HC, et al., 2010; FERNANDES JMG, et al., 2014; FINKE SR, et al., 2018; RIBEIRO LG, et al., 2013).

Na comparação das médias, como pode ser observado na Tabela 2, nota-se uma diferença de 6 pontos absolutos entre o pré-teste e o pós-teste imediato nos dois grupos ( $\mathrm{A}$ e $\mathrm{B}$ ), representando um aparente acréscimo no conhecimento a curto prazo, corroborando os resultados semelhantes obtidos por outros autores (OTTONI H, 2015; BRASLOW A, et al., 1997). Além disso, o desempenho três meses após de 7.07 ( \pm 1.89 ) em média de acertos no Grupo A pode ser considerado um ganho razoável de conhecimento por parte dos alunos em médio prazo, apesar do decréscimo em relação aos resultados aferidos imediatamente após o treinamento. Esse decréscimo sinaliza queda na curva de aprendizagem quando o treinamento não é periódico, havendo a necessidade de treinamentos regulares para a população leiga. O projeto "Kids save lives", por exemplo, recomenda treinamento anual de SBV para a idade escolar, reconhecendo ao mesmo tempo a dificuldade de implementação (HAVERMANN CS, et al., 2020; BOTTIGER BW e AKEN HV, 2015; EISENBERG M, et al., 1995). 
Ainda na Tabela 2, o desempenho do grupo teórico-prático (Grupo B) aparece com melhor desempenho no pós-teste após 3 meses. Dessa maneira, a curto e médio prazo, o treinamento teórico-prático apesar de aparentar melhor rendimento em relação ao Grupo A, a comparação das médias mostrou não haver significância estatística ( $p>0,05)$, semelhante ao que mostra o estudo de Miotto HC, et al. (2010).

Nossos achados apresentam limitações relacionadas ao tamanho amostral e ao interesse e nível de atenção dos sujeitos da pesquisa envolvidos, uma vez que o tema não é debatido de forma habitual na escola. Miotto HC, et al. (2010) concluíram que não há diferença na avaliação entre o grupo de ensino apenas teórico versus teórico-prático, porém evidencia um desempenho pior na avaliação prática por parte do grupo com ensino exclusivamente teórico, o que não foi avaliado 3 meses após o treinamento em nosso estudo e pode ter sido um fator limitador em não ter demonstrado a diferença entre os grupos. Com isso, o autor conclui que o treinamento exclusivamente teórico melhora a capacidade cognitiva (conhecimento), mas não a psicomotora em realizar uma RCP eficaz. (OTTONI H, 2015; BRASLOW A, et al., 1997; EISENBERG M, et al., 1995).

\section{CONCLUSÃO}

Não houve diferença entre os grupos durante as avaliações, apesar do declínio na taxa de retenção de conhecimentos evidenciados na avaliação realizada três meses após a instrução. Concluímos que é necessário regularidade nos treinamentos para a população leiga, a exemplo do que já é feito para profissionais da saúde, com início na educação básica. O socorrista em potencial precisa desenvolver confiança suficiente para que perceba o quanto é capaz de estar habilitado para realizar uma RCP eficaz.

\section{REFERÊNCIAS}

1. AEHLERT B. ACLS, Suporte avançado de vida em cardiologia: Emergências Cardiológicas. 4. ed. Rio de Janeiro: Elsevier. 2013; 406 p. Tradução de: ACLS, study guide, 4th ed.

2. AMERICAN HEART ASSOCIATION. Destaques das Diretrizes de RCP e ACE 2020. Disponível em: https://cpr.heart.org/-/media/cpr-files/cpr-guidelines-files/highlights/hghlghts_2020eccguidelines_portuguese.pdf Acessado em: 08 de fevereiro de 2021.

3. BOBROW BJ, et al. The Effectiveness of Ultrabrief and Brief Educational Videos for Training Lay Responders in HandsOnly Cardiopulmonary Resuscitation: Implications for the Future of Citizen CPR Training. Circulation: Cardiovascular Quality and Outcomes. 2011; 4(2):220-226.

4. BOTTIGER BW, AKEN HV. Kids save lives - Training school children in cardiopulmonary resuscitation worldwide is now endorsed by the World Health Organization (WHO). Resuscitation. 2015; 94(1):5-7.

5. BRASLOW A, et al. CPR training without and instructor: development and evaluation of a video self-instructional system for effective performance of cardiopulmonary resuscitation. Resuscitation. 1997; 34(3):207-220.

6. CUMMINS RO, et al. Improving survival from sudden cardiac arrest: the "chain of survival". A Statement for health professional from the Advanced Cardiac Life Support Subcommittee and the emergency cardiac care Committee, American Heart Association. Circulation. 1991; 83(5): 1832-47.

7. EISENBERG M, et al. CPR instruction by videotape: results of a community project. Annals of emergency medicine. 1995; 198-202.

8. FERNANDES JMG, et al. Ensino de Suporte Básico de Vida para Alunos de Escolas Pública e Privada do Ensino Médio. Arq. Bras. Cardiol. 2014; 102(6):593-601.

9. FINKE SR, et al. Gender aspects in cardiopulmonary resuscitation by schoolchildren: A systematic review. Resuscitation. 2018; 125(1):70-78.

10. GONZALEZ MM, et al. I Diretriz de Ressuscitação Cardiopulmonar e Cuidados Cardiovasculares de Emergência da Sociedade Brasileira de Cardiologia. Arq. Bras. Cardiol. 2013; 100(2):105-113.

11. GORDON PN, et al. As seen on TV: observational study of cardiopulmonary resuscitation in British television medical dramas. BMJ. 1998 Sep 19; 317(7161):780-3.

12. HAINZENREDER TB, et al. Avaliação do ponto de vista dos pacientes sobre manobras de reanimação cardiorrespiratória. Salão de Iniciação Científica. Livro de resumos. Porto Alegre: UFRGS/PROPESQ, 1996. 229p.

13. HASENEDER R, et al. Impact of instructor professional background and interim retesting on knowledge and selfconfidence of schoolchildren after basic life support training: a cluster randomised longitudinal study. Emergency Medicine Journal, 2019; 36:239-244.

14. HAVERMANN CS et al. Implementation of Basic Life Support training in schools: a randomised controlled trial evaluating self-regulated as alternative training concept. BMC Public Health. 2020; 20(1):1-9.

15. ISBYE DL, et al. Skill retention in adults and in children 3 months after basic life support training using a simple personal resuscitation manikin. Resuscitation. 2007 Aug; 74(2):296-302.

16. ISERBYT P. The effect of Basic Life Support (BLS) education on secondary school students' willingness to and reasons not to perform BLS in real life. Acta cardiologica, 2016; v. 71, n. 5, p. 519-526. 
17. LAU Y, et al. Effectiveness of digital resuscitation training in improving knowledge and skills: A systematic review and meta-analysis of randomized controlled trials. Resuscitation. 2018; 131(1):14-23.

18. MAKINEN M et al. Healthcare professionals hesitate to perform CPR for fear harming the patient. Resuscitation. 2014; 85(11):181-2.

19. MIOTTO HC, et al. Efeito na RCP Utilizando Treinamento Teórico versus Treinamento Teórico-Prático. Arq. Bras. Cardiol. 2010; 95(3):328-331.

20. NIELSEN AM, et al. Can mass education and a television campaign change the attitudes towards cardiopulmonary resuscitation in a rural community?. Scandinavian Journal of Trauma, Resuscitation and Emergency Medicine. 2013; 21(39):1-8.

21. NOLAN JP et al. Part 1: Executive summary: 2010 International Consensus on Cardiopulmonary Resuscitation and Emergency Cardiovascular Care Science With Treatment Recommendations. Ressuscitation. 2010; 81(1):1-25.

22. OTTONI H. Avaliação de Ensino e aprendizagem sobre Suporte Básico de Vida (BLS) em recrutas da Força Aérea Brasileira. Em extensão. 2015; 14(1):76-90.

23. PERGOLA AM, ARAUJO IEA. Laypeople and basic life support. Rev. esc. enferm. USP. 2009; 43(2):335-342.

24. RIBEIRO LG, etal. Estudantes de medicina ensinam ressuscitação cardiopulmonar a alunos do fundamental. Arq. Bras. Cardiol. 2013; 101(4):328-335.

25. SASSON C, et al. Predictors of survival from out-of-hospital cardiac arrest: a systematic review and meta-analysis. Circ Cardiovasc Qual Outcomes. 2010; 3(1):63-81.

26. SAVASTANO S, VANNI V. Cardiopulmonary resuscitation in real life: the most frequent fears of lay rescuers. Resuscitation. 2011; 82(5):568-71.

27. STROOBANTS J, et al. Schoolchildren as BLS instructors for relatives and friends: Impact on attitude towards bystander CPR. Resuscitation. 2014 Dec; 85(12):1769-74.

28. TABNET-DATASUS. Óbitos por causas evitáveis de 5 a 74 anos no Amazonas. Disponível em: http://www2.datasus.gov.br/DATASUS/index.php?area=02. Acessado em 08 fevereiro de 2021.

29. TONER $P$, et al. Teaching basic life support to school children using medical students and teachers in a 'peer-training' model--results of the 'ABC for life' programme. Resuscitation, 2007 Oct; 75(1):169-75.

30. TONY ACC, et al. Teaching Basic Life Support to schoolchildren: quasi-experimental study. Revista Latino-Americana de Enfermagem, 2020; v 28, e3340.

31. WINGEN S, et al. Self-confidence and level of knowledge after cardiopulmonary resuscitation training in 14 to 18-yearold schoolchildren: A randomised-interventional controlled study in secondary schools in Germany." European Journal of Anaesthesiology| EJA. 2018; 35.7: 519-526.

32. WISSENBERG M, et al. Association of national initiatives to improve cardiac arrest management with rates of bystander intervention and patient survival after out-of-hospital cardiac arrest. JAMA. 2013; 310(13):1337-84. 